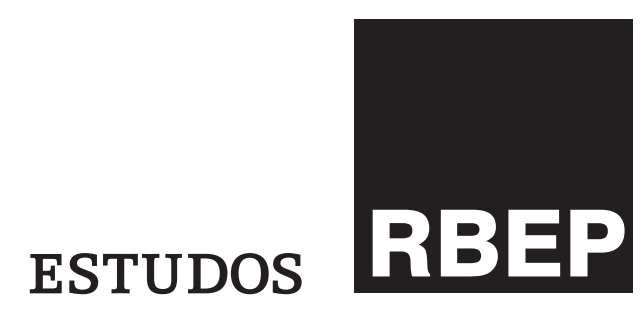

\title{
A análise do trabalho em didática profissional ${ }^{*}$
}

Pierre Pastré ${ }^{\mathrm{I}}$

http://dx.doi.org/10.24109/2176-6681.rbep.98i250.3368

\section{Resumo}

A didática profissional tem como objetivo analisar o trabalho com vistas à formação de competências. Na origem dessa abordagem, encontram-se duas correntes: a psicologia do trabalho (Faverge, Leplat), que evidenciou a dimensão cognitiva existente em qualquer trabalho; e a psicologia do desenvolvimento (Piaget, Vygotski, Vergnaud), que enfatizou o papel da conceituação na ação. Apresentam-se alguns exemplos de análise do trabalho em didática profissional, mapeando os conceitos pragmáticos que são verdadeiros organizadores da ação, no sentido em que permitem aos atores diagnosticar a situação na qual se encontram. Essa análise só pode ser feita em relação à atividade dos atores; assim, é possível visualizar a estrutura conceitual da situação, mais exatamente a representação que fazem dela.

Palavras-chave: análise do trabalho; didática profissional; conceituação; desenvolvimento cognitivo. 


\section{Abstract \\ Work analysis on professional didactics}

Professional didactics aims at analyzing work duties for the purpose of gaining competences. In the origins of this approach, there are two trends: work psychology (Faverge, Leplat), which underlines the cognitive dimension existing in every work; developmental psychology (Piaget, Vygotski, Vergnaud), which emphasizes the role of conceptualization in action. This paper offers a few examples of work analysis on professional didactics, tracing the pragmatic concepts that are the real action organizers, in the sense that they enable actors to identify the situation in which they find themselves. This analysis can only be carried from the perspective of the actors' activity; thus, it is possible to reflect on the situation's conceptual structure, or more precisely their representation of it.

Keywords: work analysis; professional didactics; conceptualization; cognitive development.

\section{Résumé \\ L'analyse du travail en didactique professionnelle}

La didactique professionnelle a pour but d'analyser le travail en vue de la formation des compétences. À l'origine de cette démarche, on trouve la rencontre de deux courants : la psychologie du travail (Faverge, Leplat) a mis en évidence la dimension cognitive existant dans tout travail. La psychologie du développement (Piaget, Vygotski, Vergnaud) insiste sur le rôle de la conceptualisation dans l'action. On présente dans cet article quelques exemples d'analyse du travail en didactique professionnelle, en insistant sur deux points. Il s'agit de repérer des concepts pragmatiques qui sont de véritables organisateurs de l'action, en ce sens qu'ils permettent aux acteurs de faire un diagnostic de la situation dans laquelle ils se trouvent. Or cette analyse ne peut se faire qu'en allant au-delà du travail prescrit: c'est en analysant l'activité des acteurs qu'on peut repérer la structure conceptuelle de la situation, plus exactement la représentation qu'ils s'en font.

Mots-clés: analyse du travail; didactique professionnelle; conceptualisation; développement cognitif.

Ao observar a gênese da didática profissional, verifica-se que a análise do trabalho ocupa nela, desde o início, um lugar central. Isso se 
explica, em grande parte, pelas origens históricas dessa nova disciplina. Durante a primeira etapa de seu desenvolvimento, a formação profissional contínua elaborou, prática e teoricamente, uma engenharia de formação profundamente inovadora. A análise do trabalho teve dificuldades para encontrar seu lugar nessa disciplina: a ênfase estava na concepção e na construção de dispositivos de formação. A didática profissional quis, por sua vez, produzir os meios para chegar a uma análise do trabalho efetiva. Para tanto, buscou inspiração no encontro de duas correntes teóricas consideradas profundamente convergentes: a da conceituação da ação, de G. Vergnaud (1992), advinda do movimento piagetiano; e a da psicologia do trabalho de língua francesa (Leplat, 2000), que enfatizou particularmente a dimensão cognitiva da atividade profissional. Mas há outro ponto que convém sublinhar já nesta introdução: em didática profissional, a análise do trabalho responde por um duplo objetivo - construir conteúdos de formação correspondentes à situação profissional de referência e utilizar as situações do trabalho como suporte para a formação de competências. Em suma, conforme indica o título do número 139 da revista Educação Permanente (1999), trata-se de aprender (d)as situações, no duplo sentido que o "(d)as" atribui à expressão. ${ }^{1}$

\section{Convergência de duas correntes teóricas em torno do par situação-atividade}

\section{A psicologia do trabalho de língua francesa}

A psicologia do trabalho trouxe técnicas e métodos de análise do trabalho à didática profissional e forneceu, sobretudo, uma forma de examinar a dimensão cognitiva da atividade profissional: provavelmente, essa dimensão permitiu que o enxerto funcionasse. Em extensa introdução, são citados três autores cujas concepções convergem com as de Pastré. O primeiro é Faverge, que sustenta que o trabalho é uma conduta pela qual um ator busca se adaptar, por meio de uma abordagem ativa, às características de uma situação. Faverge utiliza pouco o termo atividade, mas a ideia ocupa nele um lugar central. Essa é a razão pela qual $A$ análise do trabalho é um livro fundante. Em Faverge, encontra-se pela primeira vez uma análise cognitiva da atividade profissional: trabalhar comporta diagnóstico de situações, resolução de problemas, planejamento e uso de estratégias. (Ombredane; Faverge, 1955).

Leplat $(1995,2000)$ continua o trabalho de Faverge e desenvolve dois temas. O primeiro, o mais conhecido em seus escritos, busca distinguir e articular aquilo que, no trabalho, tange à tarefa prescrita e à atividade: há sempre mais no trabalho real do que na tarefa prescrita. Isso não quer dizer que todos os operadores sejam de alguma forma rebeldes, sempre tentando fazer as coisas de modo diferente do que fora determinado. Significa que há no trabalho uma parte de criação e de adaptação aos eventos e que o estágio de efetivação do trabalho nunca se reduz ao
Nota dos tradutores: no original em francês "apprendre des situations". 
planejado, ou seja, confrontada com a inesgotável densidade do real, a atividade acaba sempre transbordando a tarefa previamente delineada. $\mathrm{O}$ segundo tema desenvolvido por Leplat é muito mais discreto - Nyssen e De Keyser (1993), em um artigo em homenagem ao autor, sublinham isso com bastante refinamento. Leplat não se detém na oposição frontal entre o trabalho prescrito e o trabalho real e introduz um terceiro termo nesse debate, que chama "a estrutura cognitiva da tarefa". Isso quer dizer que o que vai definir a situação de trabalho não está unicamente relacionado com as modalidades da prescrição, mas inclui também certas dimensões objetivas desse contexto, que vão orientar a atividade. Assim, pode-se dizer que a análise do trabalho desenvolvida por Leplat é organizada em torno do par situação-atividade, situação incluindo a prescrição e a estrutura cognitiva da tarefa e servindo de introdução à análise da atividade, que continua sendo o objetivo.

O terceiro autor, muito próximo da abordagem da didática profissional, é Savoyant (1979), que se inspirou bastante na psicologia soviética do trabalho. Esse autor utiliza uma teoria de Galpérine, que distingue na ação três tipos de operações: execução, controle e orientação. Todo trabalho implica esses três tipos de operações. As duas primeiras, execução e controle, são bem visíveis e têm pouca chance de escapar à análise. Em compensação, a terceira, a orientação, é pouco visível; no entanto, de acordo com o autor, ela constitui o núcleo central da competência. Para um operador, ela consiste em mapear os traços da situação que servirão para guiar sua ação: é a parte propriamente cognitiva da atividade profissional. Um operador pode apoiar-se numa "base de orientação" incompleta, empírica ou racional, e entende-se que as outras operações, as de execução e de controle, serão assim afetadas. A importância dada à orientação permite precisar o sentido do par situação-atividade mencionado. As operações de orientação dependem das características da situação, mais exatamente da maneira como um operador as interpreta. Por outro lado, a orientação realça o primado da dimensão cognitiva na análise do trabalho, não no sentido em que trabalhar seja aplicar conhecimentos a dados, mas no sentido em que trabalhar é selecionar certas dimensões de uma situação para fazer delas elementos organizadores de sua ação. A junção das dimensões cognitiva e situada constitui um aporte preeminente dessa corrente de psicologia do trabalho.

\section{A corrente da conceituação na ação}

Observa-se o par situação-atividade a partir de outro caminho, aquele tomado por Vergnaud (1985) para prosseguir com o tema piagetiano da conceituação na ação. Aqui é deixada a análise do trabalho para voltar à psicologia do desenvolvimento, sendo a particularidade de Vergnaud ligar a abordagem desenvolvimental à análise didática. Pastré (1992) em seu estudo acerca da didática profissional buscou saber se o quadro teórico desenvolvido por Vergnaud podia ser aplicado à análise das situações de 
trabalho, com o intuito de explicar como se constroem e se desenvolvem competências profissionais. Esse quadro teórico foi elaborado em torno dos conceitos de esquema e de invariante operatório, emprestados de Piaget (1974), porém reinterpretados no quadro de uma teoria das situações. No fundo, os aportes da psicologia do trabalho mencionados tinham o mérito de insistir na dimensão cognitiva do trabalho, mas sem precisar suficientemente em que consistia essa cognição. Com Vergnaud, a cognição se torna conceito na ação: seguindo Piaget, ele lembra que há duas formas do conhecimento, a forma discursiva e predicativa e a forma operatória e enativa, que é geneticamente primeira e que permite compreender como a ação é organizada e como se constroem as competências.

Vergnaud parte de uma ideia simples: para analisar as competências, é preciso analisar a ação eficaz. Ora, esta é organizada. Analisar as competências equivale pois a analisar a organização da ação. A ação eficaz manifesta ao mesmo tempo invariância e regularidade, mas também flexibilidade e capacidades de adaptação às circunstâncias. O conceito de esquema permite dar conta da invariância e da adaptabilidade: a ação é flexivelmente organizada em torno de um núcleo invariante, pois não pode haver organização sem invariância, mas com grande capacidade de se adaptar até certo ponto às variações da situação. Esse esquema é uma organização hierarquizada segundo vários níveis, desde o temporal até o conceitual. A relevância do conceito de esquema está em propor um quadro teórico que trata da organização da ação, insistindo na flexibilidade e nos diferentes níveis hierárquicos que constituirão os apoios para a análise.

Retoma-se alguns instantes o conceito de invariante operatório. Essa é a grande descoberta de Piaget, pois é encontrada aí uma teoria do conceito que se afasta fortemente das teorias habituais, aquelas que tendem a tomar como equivalentes conceitos e conhecimentos. Seria possível aproximar os invariantes operatórios e as categorias definidas por Kant, visto que, em primeiro lugar, não são objetos do pensamento, mas sim ferramentas dele; não são aquilo que se pensa, mas aquilo a partir do que se pensa. São essas ferramentas que permitem ao mesmo tempo elaborar uma representação do mundo e agir sobre ele de forma eficaz. As conservações piagetianas são tipicamente dessa espécie. Elas representam notadamente os ingredientes de uma "física" espontânea, que organiza a representação do mundo do sujeito, mas que, antes de mais nada, serve para organizar sua ação. Esse conceito de invariante operatório permite pensar as relações entre teoria e prática de outro modo: se a conceituação pode ser pensada no coração da ação, como princípio organizador, ela não pode acontecer na forma de uma teoria que viria a guiar essa ação. Essa conceituação só pode ocorrer na forma de um conhecimento em ato, aquele mobilizado, por exemplo, por um ciclista para permanecer em equilíbrio em sua bicicleta ou por um operador de guindaste para utilizar da forma mais correta o comprimento do braço de sua máquina em função da carga a ser levantada.

Se a teoria operatória tivesse parado nesse ponto, não teria sido possível inspirar-se nela para a análise do trabalho, a não ser buscando traços de um estágio alcançado por um sujeito adulto em dado momento 
de seu desenvolvimento. Falta de fato para a teoria piagetiana levar em conta as situações e suas características. O modelo teórico piagetiano permaneceu fechado em sua dimensão genética, no sentido em que o desenvolvimento é pensado como um processo maturacional interno. É pouco sensível ao peso das situações, assim como à importância das mediações efetuadas por outrem. No fundo, o desenvolvimento cognitivo em Piaget é o de um sujeito epistêmico, e as aprendizagens concretas são apenas aplicações desse desenvolvimento genético estrutural. Realçando um pouco o traço: na perspectiva piagetiana, o trabalho não é um meio de desenvolvimento; ele pode tão somente fornecer exemplos. É no lugar dado às situações no desenvolvimento que Vergnaud vem operar uma revolução copernicana. Conforme afirmou Brun ([s.d.]), "a teoria dos campos conceituais marca (uma) evolução ao dar um lugar importante às situações nas quais os esquemas se formam e evoluem. $O$ par esquemasituação é fundador de um processo de aprendizagem por adaptação ativa". Passa-se assim de uma psicologia genética, que fica marcada por um modelo biológico, a uma psicologia que inclui a mediação de outrem, em particular a didática: a análise das situações com as quais os sujeitos são confrontados e da mediação operada por outrem se torna porta de entrada para uma compreensão do desenvolvimento. Na verdade, a didática das matemáticas não é a profissional: as situações encontradas não têm as mesmas características. Mas Vergnaud (1991), com sua teoria dos campos conceituais, forneceu o elo que faltava para adaptar o quadro teórico da conceituação na ação à didática profissional: um método para analisar uma classe de situações identificando os conceitos a serem mobilizados para resolver os problemas presentes nessa classe específica.

\section{A análise do trabalho em didática profissional}

Em relação a situações didáticas clássicas, a análise da organização da ação em quadros profissionais comporta pontos específicos: a importância da prescrição, dos instrumentos e da experiência profissional. A despeito dessas diferenças, o objetivo é identificar os conceitos (os invariantes operatórios representativos de uma classe de situações) que permitem organizar uma ação eficaz.

\section{Os conceitos pragmáticos, organizadores da ação}

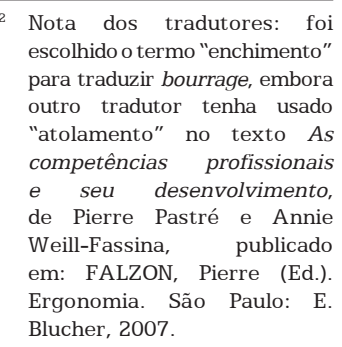
para traduzir bourrage, embora outro tradutor tenha usado "atolamento" no texto As competências profissionais e seu desenvolvimento, de Pierre Pastré e Annie Weill-Fassina, publicado em: FALZON, Pierre (Ed.). Ergonomia. São Paulo: E. Blucher, 2007.

Parte-se de uma pesquisa efetuada sobre a condução de prensas de injeção em moldagem plástica para operários especializados (Pastré, 1992). O principal resultado foi que os operadores funcionam segundo estratégias que dependem do nível de conceituação da situação feita por eles, que equivale à elaboração do conceito (pragmático) de enchimento. ${ }^{2}$ Este pode ser definido como o estado de equilíbrio e de desequilíbrio entre duas pressões: aquela exercida pela máquina sobre a matéria a ser 
injetada e aquela recebida dessa matéria. O enchimento não é diretamente observável: seu valor deve ser inferido a partir de um indicador, a existência ou não de um movimento da parte móvel da máquina em um momento preciso do ciclo de fabricação. Quando o enchimento está bom, o regime de funcionamento da máquina é normal; quando está desequilibrado, esse regime fica degradado e gera defeitos nos produtos. Pode-se, portanto, reconstituir o raciocínio de um operador perito da seguinte maneira: ele começa por fazer um diagnóstico da situação, identificando o regime de funcionamento da máquina em um dado momento. Para isso, avalia o valor do enchimento a partir de um indicador, a presença ou a ausência de movimento da parte móvel da máquina. Em função do regime de funcionamento que ele inferiu, adapta as regras de ação características da profissão à situação para corrigir os defeitos nos produtos. Um operador que não conceituou o fenômeno de enchimento não é capaz de fazer esse tipo de diagnóstico: ele apenas aplica as regras da profissão, que conhece bem. Quando o regime de funcionamento da máquina é normal, tudo ocorre bem e sua ação é eficaz. Em compensação, quando o regime está degradado (quando o enchimento não está equilibrado), o operador acaba falhando e não consegue corrigir os defeitos nos produtos. O resultado dessa análise equivale a dizer que o conceito pragmático de enchimento é o elemento central na organização da ação eficaz.

Existem conceitos pragmáticos na maioria das atividades profissionais e podem ser caracterizados de acordo com três propriedades.

Os conceitos pragmáticos servem principalmente para fazer diagnóstico de situação com vistas à ação eficaz. Isso quer dizer que sua função não é descrever objetivamente um estado do mundo, por exemplo, estabelecer relações de determinação existentes entre variáveis. Sua visada não é epistêmica, mas pragmática: analisar uma situação para ter uma ação eficaz. Ora, um diagnóstico de situação não pode se contentar em ser aproximativo ou global: é preciso selecionar aquilo que na situação é verdadeiramente pertinente. Os peritos extraem algumas informações da situação. Frequentemente, eles se concentram em um detalhe, ou pelo menos no que parece ser um detalhe para um novato, indo diretamente ao essencial. A articulação conceito-indicador é fundamental. No caso da pesquisa em moldagem plástica, o movimento da parte móvel da máquina que serve de indicador é um fenômeno difícil de apreender, quase não perceptível para um olho pouco exercitado, e só é observado quando lhe é dado sentido em relação ao conceito de enchimento. A visada pragmática se traduz, portanto, numa dimensão semântica: trata-se de construir relações de significação entre indicadores e variáveis funcionais para poder fazer um diagnóstico da situação.

Pode-se aproximar os conceitos pragmáticos dos cotidianos, tais como os concebe Vygotski. Os conceitos pragmáticos geralmente não são definidos. A concepção de enchimento fornecida foi elaborada evidentemente sob a supervisão de peritos. Mas não são conceitos implícitos: nas oficinas, fala-se em enchimento permanentemente (sem defini-lo). Os antigos os transmitem aos novatos; eles lhes mostram situações em que as máquinas são mal reguladas. Nessa troca cotidiana, há uma articulação permanente 
entre o indicador observável e o conceito. Os conceitos pragmáticos possuem assim um duplo status: são objeto de troca no âmbito dos saberes de profissão (métier), eles pertencem à prescrição em sentido amplo; são transmitidos dos antigos aos novatos, por uma mistura de verbalização e de demonstração, assim como os conceitos cotidianos de Vygotski. Mas a transmissão não basta para chegar ao verdadeiro conceito, é preciso ainda que os conceitos pragmáticos sejam objeto de construção do sujeito - visto que o que é transmitido é uma representação e que ela só se torna conceito graças à atividade construtiva do indivíduo. Tomam-se como prova as diferenças de estratégias entre operadores: todos foram instruídos sobre o enchimento, mas somente aqueles que construíram o conceito podem utilizá-lo para fazer um diagnóstico do regime de funcionamento. Os outros se contentam em aplicar regras de profissão.

Um conceito pragmático é característico de uma situação profissional e nisso se distingue dos conceitos cotidianos de Vygotski. Um conceito pragmático é específico de uma classe de situações bastante delimitada: um operador de prensas de injeção não mobilizará os mesmos conceitos pragmáticos que um operador de torno ou de fresa, tampouco isso ocorrerá com um agricultor cultivando trigo ou milho, um cozinheiro, um médico ou uma assistente social. Ao contrário dos conceitos cotidianos que têm uso muito amplo, os conceitos pragmáticos são, pois, muito específicos às dimensões da situação profissional para a qual eles organizam a ação eficaz. Encontra-se aí o par situação-atividade tal como foi analisado em Vergnaud: é preciso identificar as dimensões características da situação na sua especificidade para compreender como os sujeitos organizam sua ação por meio de uma conceituação mais ou menos profunda. Assim, é possível dizer que os conceitos pragmáticos estão presentes de duas maneiras: na situação, não a título de conceitos, mas de dimensões pertinentes ao real, que se revela indispensável para ter uma ação eficaz; e na representação dos atores (quando estes operam uma conceituação adequada), como princípios de organização da ação eficaz. Um conceito pragmático se torna representativo de um campo profissional, mas também de um tipo de estratégia que um ator é capaz de mobilizar.

\section{Identificação dos conceitos pragmáticos e da análise do trabalho}

Apresentou-se até aqui a pesquisa em moldagem plástica por meio de seu resultado: a descoberta do conceito pragmático de enchimento como organizador da ação. Dessa forma, tem-se o seguinte encadeamento: 1) a análise da situação permite identificar o enchimento como a dimensão central; 2) graças à avaliação do enchimento, pode-se distinguir vários regimes de funcionamento da máquina; e 3) quando se passa para a análise da atividade dos atores, constata-se que as diferentes estratégias deles são caracterizadas pela consideração, ou não, do enchimento em sua percepção da situação: ao levá-lo em conta, os operadores podem fazer diagnóstico de regime; caso contrário, eles apenas aplicam as regras de ação da profissão. 
Essa apresentação corre o risco de dar lugar a uma ilusão retrospectiva. Na realidade, a importância do enchimento não foi descoberta no estudo objetivo da situação, mas sim quando foi necessário caracterizar a atividade de resolução de problemas de diferentes operadores. Esse ponto merece uma explicação, pois evidencia uma dimensão importante da análise do trabalho em didática profissional. Pode-se dizer que essa análise se fez em dois tempos. O primeiro corresponde àquilo que se chama em ergonomia de análise da tarefa prescrita, o que forneceu três coisas: 1) uma descrição do decorrer da ação, isto é, a sucessão das etapas que caracterizam o ciclo de fabricação; 2) um conjunto de regras de ação, ou regras de profissão, que expressa o que é preciso fazer em função da situação; e 3) uma descrição do conjunto das relações de causalidade entre parâmetros de ação e variáveis de resultado. É verdade que o enchimento teve lugar de destaque nesta última descrição, mas era apenas uma dimensão, embora central, da situação. Somente com a análise da atividade dos atores foi dado ao enchimento o estatuto de organizador da ação, de fonte das diferentes estratégias dos operadores.

Após a análise da tarefa prescrita, decidiu-se construir uma simulação. Elaborou-se um gerador de situações-problema que permitia pôr em cena todo um conjunto de situações simulando a atividade dos operadores: corrigir defeitos que apareciam nos produtos fabricados. Selecionaram-se, sem hipótese pré-concebida, dez situações-problema, que foram submetidas a dez operadores, trabalhando sozinhos e sem ajuda. Com base nos resultados, constatou-se que três situações-problema não tinham o mesmo desempenho que as outras. Para explicar essas diferenças, a análise dessas situações foi retomada, descobrindo-se que a disparidade era explicada pela existência de dois regimes de funcionamento da máquina: um regime normal, correspondendo ao enchimento em equilíbrio; e um "regime compensado", correspondendo a um desequilíbrio no enchimento. Isso permitia verificar as diferentes estratégias dos operadores: aqueles que tinham conceituado o enchimento podiam se apoiar num diagnóstico de regime de funcionamento, o que se determinava pelo padrão característico no encadeamento das operações; eles eram os únicos que dominavam as situações-problema relativas ao regime compensado. Aqueles que não tinham construído o conceito de enchimento não elaboravam um diagnóstico (outro padrão no encadeamento de suas operações); eles tinham grande dificuldade com problemas de regime compensado, o que podia ser traduzido por um fracasso definitivo ou por soluções capengas feitas por meio de tentativas e erros.

Pode-se, pois, dizer que a observação do trabalho procedeu de forma curiosamente retrospectiva: ao buscar compreender os resultados da análise da atividade dos operadores, emitiu-se a hipótese de suas classes de situações e, ao explicar essa diferença, o conceito de enchimento foi retomado. Enquanto a análise da tarefa prescrita só tinha feito do enchimento uma variável entre outras, central sem dúvida, mas não um conceito organizador da ação, a análise da atividade de resolução de 
problemas dos operadores permitiu atribuir ao enchimento um estatuto de conceito pragmático. Desse modo, a articulação entre a análise da tarefa prescrita e a da atividade toma forma dialética. Vê-se bem que se está lidando com um verdadeiro par situação-atividade: não se pode compreender a atividade dos operadores se não há conhecimento mínimo da situação e de suas características; mas os elementos desse contexto que serão utilizados para construção dos conceitos pragmáticos só podem ser identificados pela análise da atividade, que leva, retroativamente, a distinguir os elementos da situação que fazem sentido para o sujeito. Há assim uma análise da situação antes da análise da atividade: ela consiste em evidenciar os diferentes elementos que caracterizam o cenário. Há também uma análise da situação após a análise da atividade: é somente ela que permite identificar os organizadores da ação.

\section{O caso das situações dinâmicas: conceituação epistêmica e conceituação pragmática}

Encontrou-se abordagem semelhante na pesquisa conduzida por Samurçay, Plénacoste e Pastré (apud Pastré, 1999) sobre a aprendizagem na condução de centrais nucleares em simulador. Há seguramente enormes diferenças entre a condução de uma máquina e a de um sistema dinâmico (para um estudo detalhado, cf. Pastré, 1999); no entanto, existem pelo menos dois pontos comuns: 1) há conceitos organizadores da ação; para os sistemas dinâmicos, esses conceitos são múltiplos e formam uma rede, o que revela uma estrutura conceitual da situação; e 2) há a mesma abordagem de análise do trabalho - mapeamento de estratégias diferentes entre os operadores, quando eles são confrontados com uma situação que lhes traz um problema, e observação de que essas estratégias se fundam na identificação de regimes de funcionamento e repousam sobre um diagnóstico baseado em indicadores. Enfim, a análise dessa atividade de diagnóstico permite ter acesso a conceitos organizadores da ação.

Há, contudo, uma diferença notável entre a aprendizagem da operação de prensas e a da operação de centrais. No primeiro caso, a aprendizagem se deu quase exclusivamente "no fazer", levando a abordar conceitos "pragmáticos" -construídos para a ação, mas também na ação. Esses conceitos fazem parte de saberes de profissão, os quais representam as boas práticas. Mas seu valor epistemológico não ultrapassa geralmente um empirismo compartilhado pelos profissionais da área. No caso da condução de centrais, em que o cuidado de explicitação e de construção dos conhecimentos foi levado ao extremo, a relação entre conceitos científicos e pragmáticos impõe um problema muito diferente: há necessariamente uma forte articulação entre o modelo epistêmico da instalação e sua transformação pragmática, e é interessante ver como os novatos efetuaram a "pragmatização" de conceitos científicos. Encontra-se aí a distinção proposta entre conceitos e indicadores, com esta particularidade que, para 
a condução de centrais, os indicadores não são observáveis sensorialmente (percebidos como movimento, barulho ou odor), mas já são variáveis instrumentalizadas. Assim, variáveis (por exemplo, uma temperatura) vão servir para avaliar outras variáveis mais fundamentais para o diagnóstico, mas não diretamente acessíveis (por exemplo, uma potência). Há, pois, transformação de sistema de conhecimentos (as relações de determinação existentes entre variáveis) em sistema de diagnóstico (uma ou mais variáveis servindo de indicadores para avaliar um equilíbrio de base do sistema), ou seja, há a pragmatização de certos conhecimentos científicos. Pode-se dizer que isso é o que está em jogo na formação em simulador.

Essa aprendizagem vai acontecer no momento em que os novatos forem confrontados, na ação, com certas situações críticas. Eles percebem que nem seus conhecimentos nem a aplicação literal das prescrições são suficientes para escapar da parada de urgência. Os erros observados nos novatos foram de dois tipos: descobrem as coisas tarde demais ou confundem o "sintoma com a doença", o que serve de indicador e remete a um dos equilíbrios de base. Outra constatação: a repetição pura e simples da ação é pouquíssimo eficiente para construir modelização pragmática. O que é determinante na construção desse modelo é o momento do debriefing [exame da situação] - quando se opera a conceituação da situação na sua forma pragmática e os atores descobrem, a posteriori, com seus erros, a articulação entre equilíbrios de base, indicadores e regimes de funcionamento. A prova disso é que, após esse momento de debriefing, os novatos são confrontados com situações similares e são capazes de dominá-las: eles não correm mais atrás da situação como faziam na primeira vez, estão no ritmo dela. Esse domínio novo é realmente o fruto de uma compreensão que se juntou com a ação e que doravante pode guiá-la. Isso não quer dizer que os novatos não cometam mais erros: a competência de condução comporta múltiplos elementos e não se pode reduzi-la à conceituação da situação. Mas a partir desse momento todos os elementos múltiplos de competência, habilidades, procedimentos e navegação entre as diversas tarefas podem se construir porque estão assentados numa base sólida, num diagnóstico confiável da situação.

\section{Conclusão}

Ao término deste artigo, é possível tirar três conclusões concernentes à análise do trabalho em didática profissional. A primeira é a constatação de um movimento convergente entre a evolução da psicologia ergonômica, por um lado, e a evolução da corrente da conceituação na ação, por outro. A psicologia do trabalho esteve sempre muito atenta às características das situações; não se acha nela uma análise do trabalho em geral, só há análise do trabalho situada. Mas a dimensão cognitiva da atividade profissional não deixou de ter um lugar central. Evidentemente, pode-se pensar que a evolução do trabalho moderno não é estranha a esse aspecto 
situacional. Ainda assim, colocar as operações de orientação no coração da análise da atividade, como o faz Savoyant, constitui uma abertura decisiva na direção da didática profissional. No movimento de certa forma inverso, todo o trabalho teórico de Vergnaud, que retoma por conta própria as análises piagetianas sobre a forma operatória do conhecimento como organizadora da ação, consiste em ajustar a análise cognitiva às características das situações. Estas não são mais reduzidas ao papel de exemplos ilustrativos do desenvolvimento cognitivo do sujeito, elas são analisadas como tais e é mediante as características encontradas nelas que se pode observar a atividade dos atores. As duas características da análise do trabalho em didática profissional são a cognitiva e a do trabalho situado: é preciso passar pelo estudo da situação para compreender a atividade. Mas é a análise desta que permite identificar os elementos conceituais organizadores que seus atores retêm da situação. O par situação-atividade é o núcleo teórico central da pesquisa.

Segunda conclusão: como observado na introdução da noção de conceito pragmático, a análise evidencia uma dupla função dos conceitos. Primeiro, eles têm função de organização da ação. É inútil voltar ao que foi desenvolvido a respeito do papel do conceito pragmático de enchimento no diagnóstico da situação em moldagem plástica ou a respeito do papel dos equilíbrios de base e da sua avaliação na operação de centrais nucleares. Aborda-se aqui a linha exata do que desenvolveu Vergnaud: o núcleo central de um esquema (organização da ação) é constituído de invariantes operatórios. Mas os conceitos têm também função de generalização: assim que houver conceituação, escapa-se em parte da singularidade da situação. Não há tantos esquemas quanto há situações. Um esquema cobre uma classe de situações, mais ou menos extensas. Essa função generalizadora dos conceitos é evidente quando se lida com um modelo epistêmico, mas ela é igualmente presente quando se trata de um modelo pragmático. É a razão pela qual, no que concerne ao diagnóstico das situações, pode-se pensar em esboçar a chamada semântica da ação, cujas noções de conceitos organizadores, indicadores e regimes de funcionamento poderiam constituir os primeiros elementos.

Terceira conclusão: a análise do trabalho em didática profissional se assemelha ao espírito de escada. ${ }^{3}$ Nela, encontra-se o essencial quase sempre a posteriori. É inútil tentar fazer coincidir na aprendizagem a ação e sua compreensão. Sempre há um intervalo, que é afinal uma das grandes chances para o pensamento. Pois o que não se consegue fazer no decorrer da ação, pode ser alcançado mais tarde, quando finalmente se compreende o sentido do que é feito e de todos os erros. Isso vale para novatos em situação de aprendizagem ao construírem o modelo pragmático no qual

3 Nota dos tradutores: L'esprit d'escalier no original; expressão francesa explicada por Pastré na frase subsequente do texto: "encontramos o essencial quase sempre a posteriori". repousará sua capacidade de diagnosticar uma situação. Mas é provável e igualmente válido para o pesquisador: há, como mencionado, uma análise da situação antes da análise da atividade. Tudo acontece como se fosse preciso recorrer à observação do que fizeram efetivamente os operadores, para identificar o que, na situação, faz de fato sentido para 
eles. Daí essa curiosa torção que se opera na análise feita de voltas e reviravoltas, hesitante em aparência, mas que constrói sua inteligência a partir de uma integração progressiva de elementos que só são dados no interior de uma história.

\section{Referências bibliográficas}

BRUN, J. Actes du colloque de Suresnes: qu'est-ce que la pensée ?. [s.n.: s.l., s.d.].

DE KEYSER, V.; NYSSEN, A.-S. Les erreurs humaines en anesthésie. Le Travail humain, Paris, v. 56, n. 2-3, p. 243-266, 1993.

DE MONTMOLLIN, M. L'intelligence de la tâche. Berne: Peter Lang, 1984.

LEPLAT, J. Erreur humaine, fiabilité humaine dans le travail. Paris: A. Colin, 1985.

LEPLAT, J. L'analyse psychologique de l'activité en ergonomie.

Toulouse: Octares, 2000.

OMBREDANE, A.; FAVERGE, J.-M. L'analyse du travail. Paris: PUF, 1955.

PASTRÉ, P. Requalification des ouvriers spécialisés et didactique professionnelle. Education Permanente, Paris, n. 111, p. 33-54, 1992.

PASTRÉ, P. Le rôle des schèmes et des concepts dans la formation des compétences. Performances Humaines et Techniques, n. 71, p. 21-28, 1994.

PASTRÉ, P. La conceptualisation dans l'action: bilan et nouvelles perspectives. Education Permanente, Paris, n. 139, p. 13-35, 1999.

PASTRÉ, P.; WEILL-FASSINA, A. As competências profissionais e seu desenvolvimento. In: FALZON, P. (Ed.). Ergonomia. São Paulo: Blucher, 2007. cap. 13.

PIAGET, J. Réussir et comprendre. Paris: PUF, 1974.

RASMUSSEN, J. Information processing and human-machine interaction. Amsterdam: North Holland, 1986. 
SAVOYANT, A. Eléments d'un cadre d'analyse de l'activité: quelques conceptions essentielles de la psychologie soviétique. Cahiers de Psychologie, Paris, n. 22, p. 29-42, 1979.

VERGNAUD, G. Concepts et schèmes dans une théorie opératoire de la représentation. Psychologie Française, n. 30, p. 248-252, 1985.

VERGNAUD, G. La théorie des champs conceptuels. Recherches en didactique des mathématiques, n. 10, p. 132-169, 1991.

VERGNAUD, G. Approches didactiques en formation d'adultes. Education Permanente, Paris, n. 111, p. 21-31, 1992.

Recebido em 17 de abril de 2017.

Aprovado em 18 de julho de 2017. 